\title{
Computer Plotting of Drill Hole Geochemical Data (SECTION.REV 1 User's Guide)
}

by

Carol Withrow

July 1980

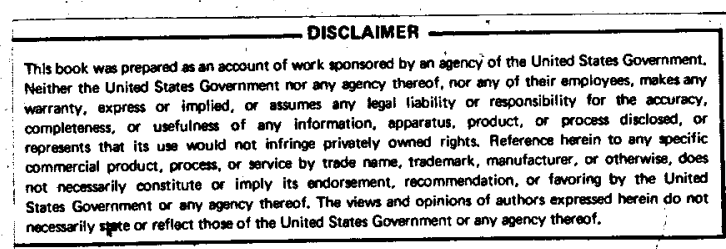

EARTH SCIENCE LABORATORY

UNIVERSITY OF UTAH RESEARCH INSTITUTE

420 Chipeta Way, Suite 120

Salt Lake City, Utah 84108

\author{
Prepared for the \\ DEPARTMENT OF ENERGY \\ DIVISION OF GEOTHERMAL ENERGY \\ UNDER CONTRACT NO. DE-ACO7-80ID12079
}




\section{DISCLAIMER}

This report was prepared as an account of work sponsored by an agency of the United States Government. Neither the United States Government nor any agency Thereof, nor any of their employees, makes any warranty, express or implied, or assumes any legal liability or responsibility for the accuracy, completeness, or usefulness of any information, apparatus, product, or process disclosed, or represents that its use would not infringe privately owned rights. Reference herein to any specific commercial product, process, or service by trade name, trademark, manufacturer, or otherwise does not necessarily constitute or imply its endorsement, recommendation, or favoring by the United States Government or any agency thereof. The views and opinions of authors expressed herein do not necessarily state or reflect those of the United States Government or any agency thereof. 


\section{DISCLAIMER}

Portions of this document may be illegible in electronic image products. Images are produced from the best available original document. 
NOTICE

This report was prepared to document work sponsored by the United States Government. Neither the United States nor its agent, the United States Department of Energy, nor any Federal employees; nor any of their contractors, subcontractors or their employees, makes any warranty, express or implied, or assumes any legal liability or responsibility for the accuracy, completeness, or usefuiness of any information, apparatus, product or process disciosed, or represents that its use would not infringe privately owned rights.

\section{NOTICE}

Reference to a company or product name does not imply approval or recommendation of the product by the University of Utah Research Institute or the U.S. Department of Energy to the exclusion of others that may be suitable. 


\section{TABLE OF CONTENTS}

Page

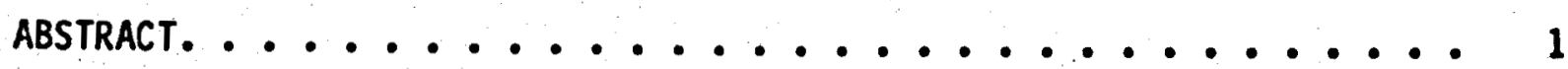

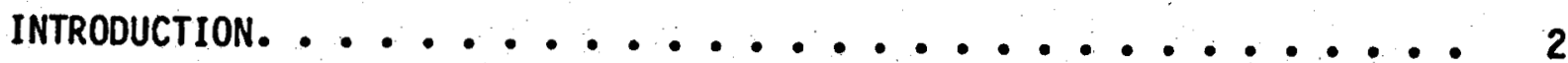

I. INITIAL DATA ORGANIZATION . $\ldots \ldots \ldots \ldots$

II. SEC-10 USAGE. ...................... 5

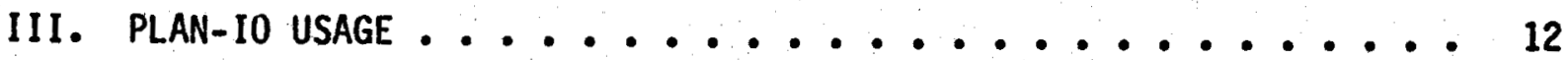

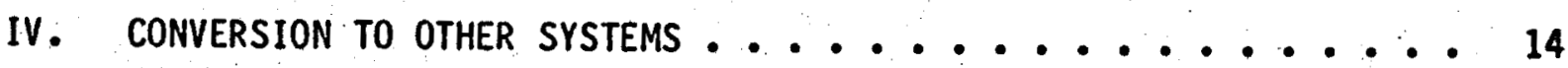
APPENDIX A

Flow Charts........................ APPENDIX B

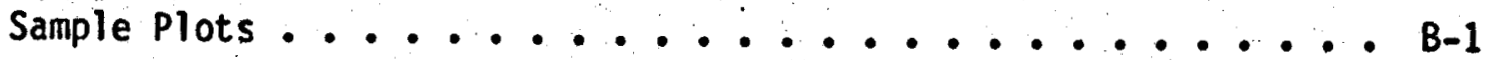
APPENDIX C

File Structure .................... c-1 APPENDIX D

Examples of Terminal Sessions. . . . . . . . . D-1

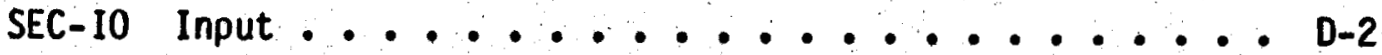

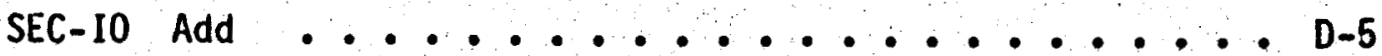

SEC-IO Edit ................... D-8

SEC-IO List .................. D-11

SEC-10 Move ................... D-15

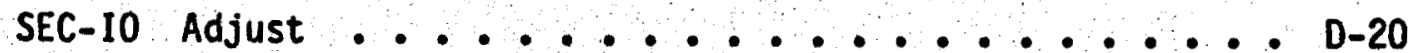

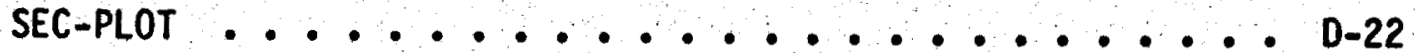




\section{ABSTRACT}

SECTION is a program package that provides plots of core sample geochemical data for any or all drill holes in a given area projected onto any predetermined section line. Plot size is user-defined by keyboard input. Holes are plotted in cross section as straight lines defined by collar coordinates, bearing angle, dip angle and length. The program is applicable to small problem areas with relatively short drill holes that are approximately straight. The program is implemented on the University of Utah UNIVAC 1108 computer system. The plotting functions are accomplished by using a plotting library that is similar to a Calcomp subroutine library. 


\section{INTRODUCTION}

This program package is designed to plot core sample data for any or all drill holes in a given problem area projected onto any predetermined section line. Various plot parameters including size are user-defined; however, only a straight line model of the drill hole is accommodated by this program.

SECTION is a package of two interactive programs named SEC-IO and SEC-PLOT which communicate with each other by means of referencing a common direct-access data file. SEC-IO is concerned with constructing this data file by means of keyboard input. It also allows this file, called the work file, to be manipulated in various ways, such as editing, listing, and storing on a master file called the merge file. SEC-PLOT reads the work file, solicits plot parameters from the user, and generates plots.

These programs were designed to provide maximum output flexibility with minimum expense while maintaining a simple man-computer dialogue. This report discusses all facets of preparing and formatting data and using the programs.

This system was designed by Robert $W$. Bamford. Programming was by $D . T$. Purvance. Modifications were programmed by Carol Withrow. 


\section{Initial data organization}

Given a problem area (i.e., a cluster of drill holes and an assemblage of composite sample data) the first step is to index or number manually all drill holes from 1 to $N$ and all sample intervals from 1 to $M$. This assigns to each drill hole and to each sample interval a computer name that is unique to the problem area. Drill hole and sample interval indices can be assigned in any pattern but, for obvious clerical reasons, drill holes should be indexed from west to east (or north to south) and sample intervals indexed beginning at the top of drill hole 11 and ending at the bottom of $A N$ ( $N=$ number of drill holes in the problem area).

Once indexing is complete, two booking tables can be constructed. One table lists drill hole collar coordinates, dip, bearing and length, and the other lists sample interval footages and corresponding geochemical data.

\section{A. Table 1 -. Drill Lab Data}

To project a drill hole onto a sectional plane, six numbers which describe the drill hole in three-dimensional space are needed. They are: $(X, Y)$ collar coordinates, collar elevation, dip from vertical, bearing of dip and length. To list this information in an orderly fashion, Table 1 should be tabulated as follows:

TABLE 1

DH Index collar ${ }^{1} Y$-coord collar $X$-coord collar elev bearing dip length
1

Collar map coordinates for a drill hole are measured relative to a chosen problem area's origin. The positive $X$-coordinate axis is defined to run from west to east, and the positive $\gamma$ axis from south to north. Collar elevation is given from mean sea level. Collar coordinates can be given in untts of feet or meters. Dip is measured in degrees from the horizontal. Bearing of dip is measured in degrees clockwise from north.

B. Table 2 -- Sample Interval Footage and Geochemical Data

Having indexed core sample intervals, a second table is to be constructed as shown below: 
TABLE 2

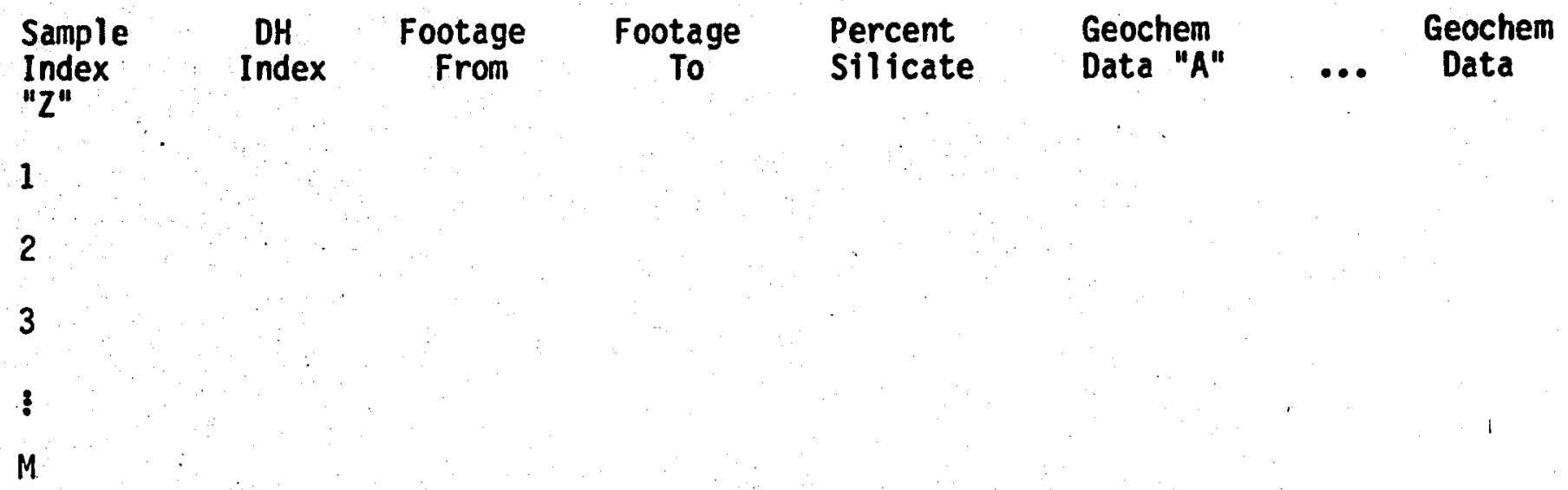

Sample intervals are not numbered by drill hole but by problem area. Therefore each sample interval is assigned an index number corresponding to its drill hole. Many samples will have the same drill hole index. This is tabulated in column 2, "DH Index." Sample interval "from" and "to" footages, or beginning and ending footage measurement, are assumed to be measured in true length down a drill hole. Geochem data types " $A$ " and so on are listings of any type of analysis done on the sample. 


\section{SEC-IO Usage}

Once data is on paper as explained above, it must be placed in computer storage. An interactive input/add/edit/list/move/adjust program, SEC-IO, is used to do this. This program easily allows the user to manipulate the data without having to be concerned with the details of manipulating data files.

There are three kinds of keyboard input to be supplied by the user. Alphanumeric input can be any keyboard character and is used for labels. Integer input consists of numbers only. Floating point input is a number with or without a decimal point. Both integer and floating point numbers may be preceded by a + or - sign. Keyboard input lines are always terminated with a carriage return.

A. Data record arrangement

The contents of Tables 1 and 2 are stored in a direct access data file with records numbered 1 through 207 in the following order:

\begin{tabular}{cl} 
Record Number & Contents \\
\hline 1 & all of Table 1 \\
2 & column 2, Table 2, DH Index \\
3 & column 3, Table 2, Footage From \\
4 & column 4, Table 2, Footage To \\
5 & column 5, Table 2, Silicate \\
$6-207$ & columns 6 - on, Table 2
\end{tabular}

B. Program Operation

The user is first presented with the following menu of options:

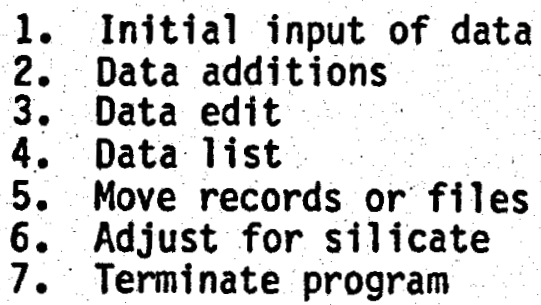

The user enters a number from 1 to 7 indicating the option he desires. The program executes the option and returns to this menu repeatediy until the option to terminate the program is selected. A flow chart depicting this may be seen in Appendix A-1. 
Terminal output for sample sessions may be seen in Appendix D. There is at least one example of each of the above options.

C. Information required for each program option follows, with the numbering and order corresponding to those in the above list.

1. Initial input

a. Record 1

1) project area name (max. 60 characters - alphanumeric input), input and output on two 30-character lines;

2) number of drill holes (integer input);

3) drill hole names (max. 6 characters, alphanumeric input):

4) collar map coordinates, collar elevation, bearing, dip and length (floating point input).

b. Records 2,3 and 4

1) number of data points for initial input (max. 700, integer input);

2) For record 2, enter next the drill hole indices from column 2 of Table 2; For record 3, enter next the "Footage From" column of Table 2; For record 4, enter next the "Footage To" column of Table 2 (all floating point input). The user will be prompted before each one of these entries with an ordinal number and a question mark; for example:

c. Other Records

1) figure number (max. 18 characters - alphanumeric input);

2) figure name (max. 36 characters - alphanumeric input);

3) sample type (max. 25 characters - alphanumeric jnput);

4) analytical method (max. 18 characters - alphanumeric input);

5) number of data points for initial input (max. 700 , integer input);

6) number of digits to the right of the data decimal point to be plotted (integer input). A maximum of 10 character positions is available. 
Use the following codes:

$-1=$ no decimal will be plotted (e.g., 123);

$0=0$ digits to right of decimal will be plotted (e.g., 123.);

$1=1$ digit to right of decimal will be plotted (e.g., 123.0);

$2=2$ digits to right of decimal will be plotted $(e . g ., 123.00)$, and so on.

7) Data values (max. 700 , real input)

Special character output features, where the value input is $V$ :

$$
\begin{aligned}
& v<\frac{\text { Input }}{-1,000,000} \\
& -1,000,000<v<0 \\
& 0<-v<1,000,000 \\
& v>1,000,000
\end{aligned}
$$

2. Data additions

a. Record 1

1) number of drill holes to add (integer input);

2) drill hole names (max. 6 characters, al phanumeric input);

3) collar map coordinates, collar elevation, bearing dip and length (floating point input).

b. Other records

1) number of sample additions (integer input); .

2) data values (floating point input).

3. Data : edit

\section{a. Record 1}

The user is presented with a menu from which he selects the item to be edited: area name, number of records entered, number of drill hole names or drill hole parameters. If drill hole parameters are selected, the program types "Enter DH index, column, value change." The column referred to is the column of Table 1. The three values are integer, integer, floating point. If one of the other items is selected, the program types the current information before soliciting the new information.

b. Other records

The user is presented with a menu from which he selects the item to be edited: figure number, figure name, sample type, analytical method, number of digits for plotting, number of data items, or data. If an item besides data is selected, the 
program types the current information before soliciting the new information. If it is the data itself to be edited, enter the sample index to be corrected and the value (integer, floating point input). To exit from this loop enter two values of zero.

4. Data list

The user is presented with two options: index or data list. The index option will provide the highest record number that has been written on the file. In addition the user may elect to view a list of record names and the number of data items in each record.

The data list option requires the following input from the user:

1) number of records to list (max. 6, integer input)

2) record numbers to be listed (integer input)

If it is desired to list record 1 , this should be done alone rather than as part of a request for listing other records. This is because the format is unique; the output of record 1 is all of Táble 1 .

5. Move

This option combines a number of functions concerned with moving data files in and out of the work space or moving records within a file. These various choices are presented as the following menu, from which the user selects by typing a number from 1 to 6 :

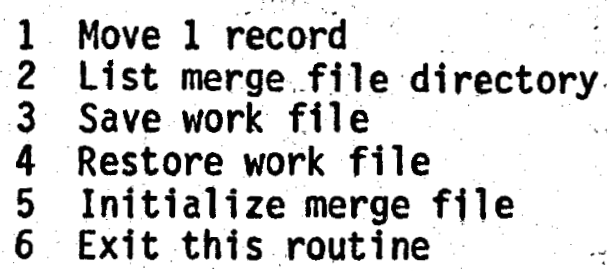

Each of these will be explained in detail using the same numbering.

$1=$ Move 1 record

This enables the user to move a record in the current data file, called the work file. The program solicits both input and output record humbers (integer input). It then reads the input record and writes this record on the output record. Any information already in the output record will be overwritten. The input record is unchanged. 
2 = List merge file directory

The merge file is a master back-up file. A number of work files may be copied into the merge file and then restored to the work space as desired. This option will produce a list of the individual work file names that are in the merge file, together with the number of data records in each file.

3 = Save work file

The current data file in the work space, called the work file, is backed up by writing it in the merge file'. A subsequent list of the merge file directory will confirm that there is a new entry.

At the end of each period of data input on a given project, the work file should be saved in the merge file, thereby permitting use of the program by other workers without loss of your data. Several files containing similar data may thus be generated for a single project. These will be identified in the merge file by the merge file index number, the project (area) name and the number of records. The work file will remain intact after "saving" until it is overwritten.

4 = Restore work file

Any file that is in the merge file can be restored to the work file. The user will be asked to provide the index number of the file (integer input). This index number can be seen in a listing of the merge file directory. Whatever is in the work space will be overwritten. The copy of the restored file that is in the merge file remains unchanged.

If a saved file is restored and changed, and it is desired to preserve this version in the merge file, then a new copy of the file is saved. This will appear in the directory as a new 11 sting with a new index number to be used for restoring it to the work space.

Files cannot be selectively deleted from the merge file.

$5=$ Initialize merge file

Initialization of the merge file effectively deletes the information th the merge file.

This file can consist of a maximum of 800 records. When it is filled a message will be produced. At this point the user will probably want to back up. the entire merge file or selected individual files in the merge 
file. Advise a programmer of your desire. After the files have been saved on tape by the programmer, and after it has been ascertained that no other user's files will be deleted, the user may initialize the merge file. A password must be provided to effect this. This is to prevent inadvertent destruction of data.

Upon initializing the file, the user must enter a file title, maximum 72 characters. This will be listed whenever a directory listing is made.

The number of work files that can be saved varies depending on the number of records written in each. A work file may contain as many as 207 records. Thus the merge file ( 800 records) will store three full work files or more than three partially full work files. The directory index includes the number of records in each file.

Initialization of the merge file in no way affects the work file.

6 = Exit this routine

The program exits the MOVE routine and produces the initial menu.

6. Adjust

This option will adjust geochemical data for silicates and write the results on a new record, the number of which is selected by the user. The same record number may be used, in which case the original data is overwritten. The formula used is:

new value $=$ old value $/(1-A / 100)$

where $A$ is the percent silicate for that particular sample. If the silicate is $70 \%$, then $A=70$ (not 70$)$. If any silicate value is outside the range of zero to 85 , it is set to one of these two numbers, whichever is closer, for the above calculation.

These silicate values must be on record 5 . If there are no silicate values, some information should be entered into record 5 in order for certain program options not to produce an error termination. The Move 1 Record capability (see previous section) is one easy way to do this.

When the new silicate-adjusted record is created, the user is requested to enter figure number and figure name for it (alphanumeric input, max. 18 and 36 characters respectively). When the prograin requests this information, it provides the 
figure number and figure name of the input record as a reminder to the user. 


\section{PLAN-PLOT Usage}

The data being stored, the final task is to define the specific parameters for plotting this data at the right size and scale and along a specific sectional line. These parameters are explained below. The names on the left are used by the program PLAN-PLOT when selecting user input. The meaning of these parameters may be further clarified by referring to the figure in Appendix B-2.

Units 1. if user units in feet.

2. if user units in meters (floating point input).

Scale Scale factor, i.e., the number of feet represented by one inch or the number of meters represented by one centimeter on the plot (floating point input).

XM Abscissa length in inches if user units are in feet or in centimeters if user units are meters $\left(<99.7^{\prime \prime}\right.$ or $<253.3 \mathrm{~cm}$, floating point input).

YM Vertical length of plot in inches if user units are in feet or in centimeters if user units are in meters $\left(<31.9^{\prime \prime}\right.$ or $<81 \mathrm{~cm}$, floating point input).

$\mathrm{CH} \quad$ Character size in inches (.07"-.2", floating point input). An entry of zero defaults to $.07 "$ ".

DMIN Minimum depth elevation in user units to be represented on depth axis (floating point input).

DMAX Maximum elevation on depth axis (floating point input).

DINT Interval between tics on the depth axis (floating point input).

XFAC The horizontal scale divided by the vertical scale (floating point input). If this is not 1 , the scaling is done in the horizontal direction.

$X_{0}, Y_{0}$ Starting map coordinates of section line, given relative to the origin of the problem area, in feet or meters (floating point input).

AZB Azimuthal bearing of section line in degrees (floating point input).

BARL Perpendicular distance (in user units) from section line beyond which sample intervals will not be plotted (floating point input). Beyond BARL drill holes are "dashed in."

The program will also require the user to enter the number of drill holes to plot, the indices of these drill holes, the number of plots to generate, and a record number of the geochemical data to go with each plot, all integer input. In addition, the following two parameters must be entered for each plot: 
MAX CONC Concentration value represented by one concentration bar length (floating point input).

CONC BAR LENGTH

The length in inches or centimeters of the concentration bar al so the maximum bar length of the sample bars. If the sample value represented exceeds this length, a small arrow will be drawn on the sample bar.

The plotting program first asks for the plot parameters explained above, including the drill hole indices to be plotted and the data record number storing the data to be plotted. Drill hole indices and record numbers are integer inputs. With this information the plotting program automatically retrieves the data on records 1 through 4 and then generates the plots. The message "PLOT N GENERATED" then appears on the terminal once for each plot. A sample plot may be seen in Appendix B-1. 
IV. Conversion to 0ther Systems

SECTION should normally be adaptable to another computer systen with only a moderate effort by a programer familiar with his system. Although the programs described here are implemented on a UNIVAC 1108, their conversion to minicomputers should not present problems of program size or computational precision.

It is necessary, of course, for the system to have a digital plotting device. SECTION uses a plotting library similar to the standard Calcomp plotting library. Any computer system that has a plotting capability similar to a Calcomp plotter will be able to provide the needed plotting functions.

Alphanumeric data storage may have to be modified for another system. The UNIVAC 1108 uses an internal six-bit character code called Fieldata. The word length is 36 bits, so alphanumeric characters are stored six to a word. If the number of characters to a word is different from six, both programs will have to be modified. The data file width may also have to be changed accordingly. Diagrams of the file structures may be found in Appendix $C$.

The work file and the merge file are direct-access files. The files are described to the programs by means of the DEFINE FILE statement that appears at the beginning of the main programs. This syntactic element is an extension of standard FORTRAN IV that is available in most but not all versions of FORTRAN. The first argument is the file length in records, and the second argument is the file width in words. SECTION files are 720 words wide. The READ and WRITE statements that reference the files use IBM direct-access syntax. If SECTION is to be developed on a system that does not have direct-access file capability, it would be difficult to make modifications that would accommodate the substitution of another file type, such as a sequential file.

Subroutine MOVE of SEC-10 requires a password to be entered before initializing a file. This password is represented in the program as the numerical contents of a word containing fieldata characters. The implementer may want to supply his own password and number.

The subroutine GETPEN of SEC-PLOT allows user-selected pen color and width, and it will have to be modified on another system. It uses a routine, CALOPR, that sends a message to the person operating the plotter. The implementer may want to delete subroutine GETPEN altogether. 



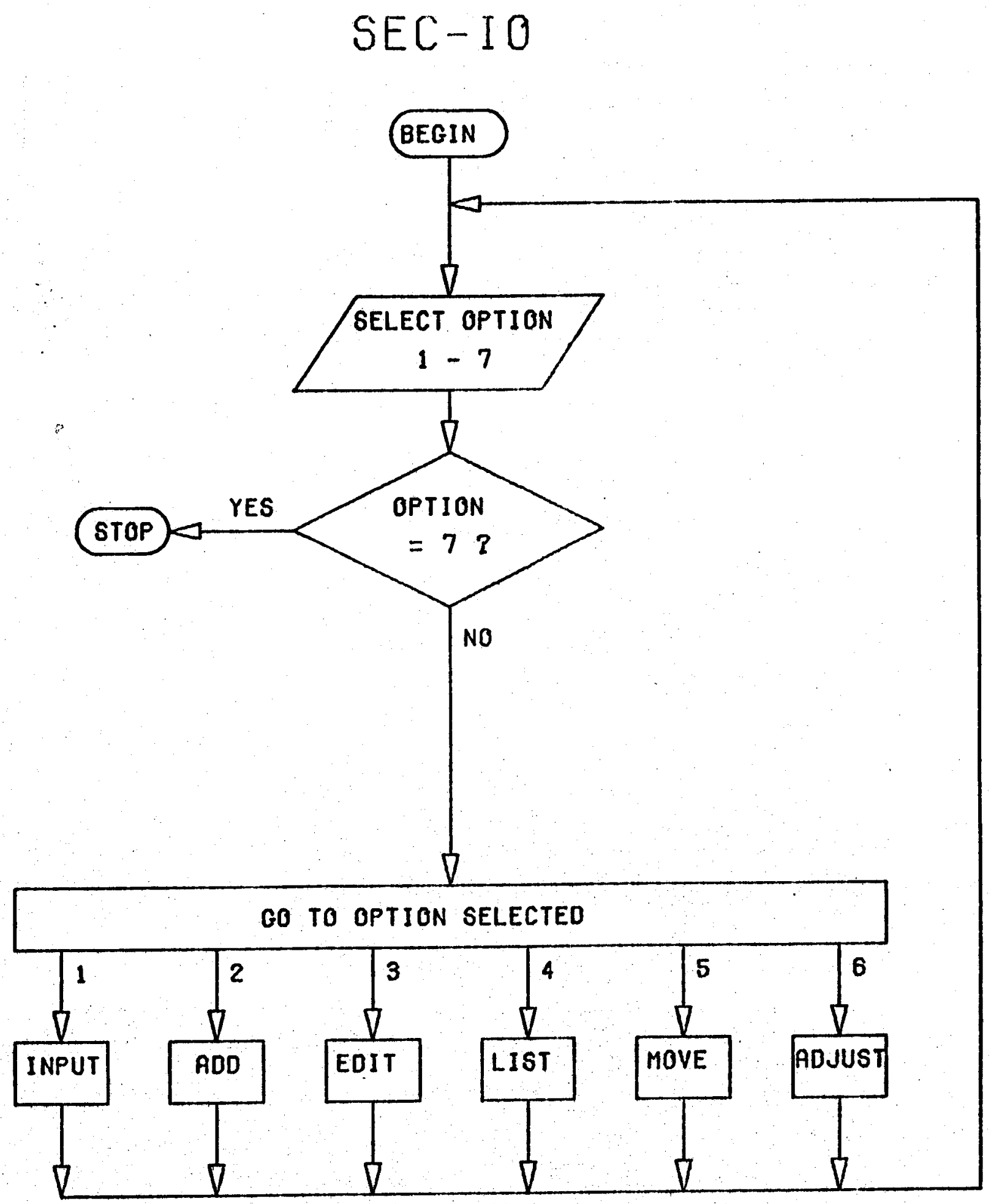




\section{SEC-PLOT}

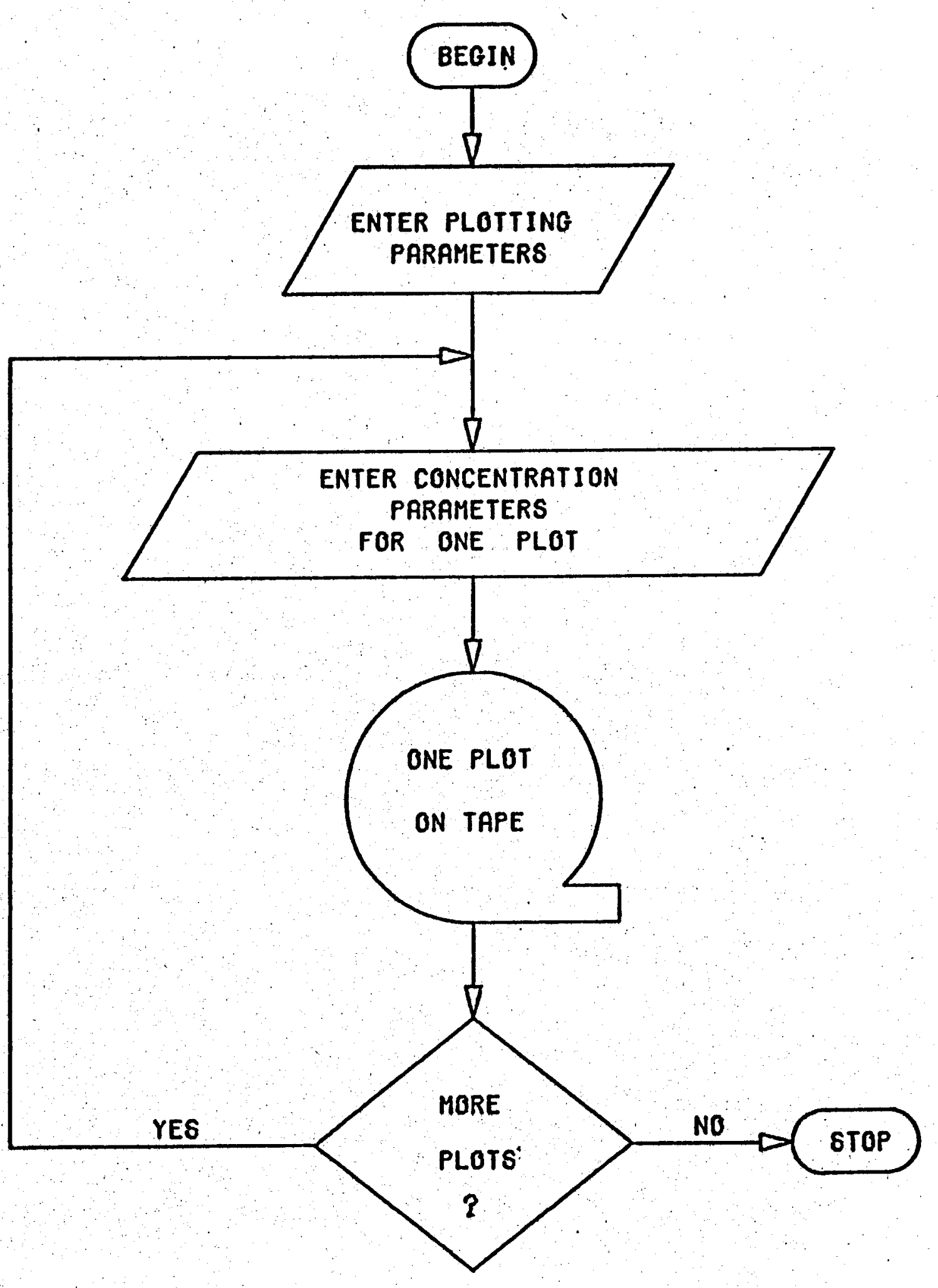


Appendix B

Sample Plots 


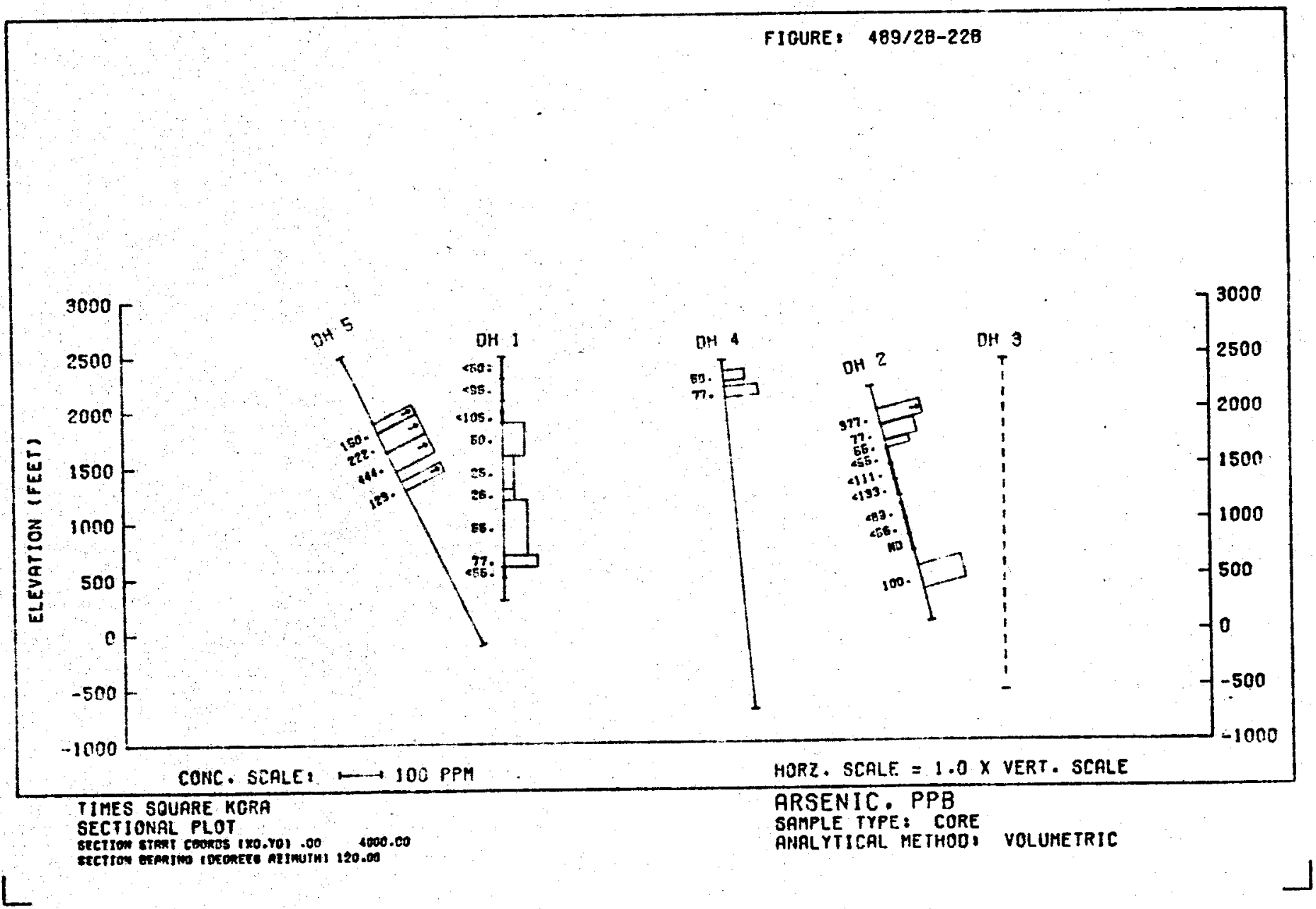




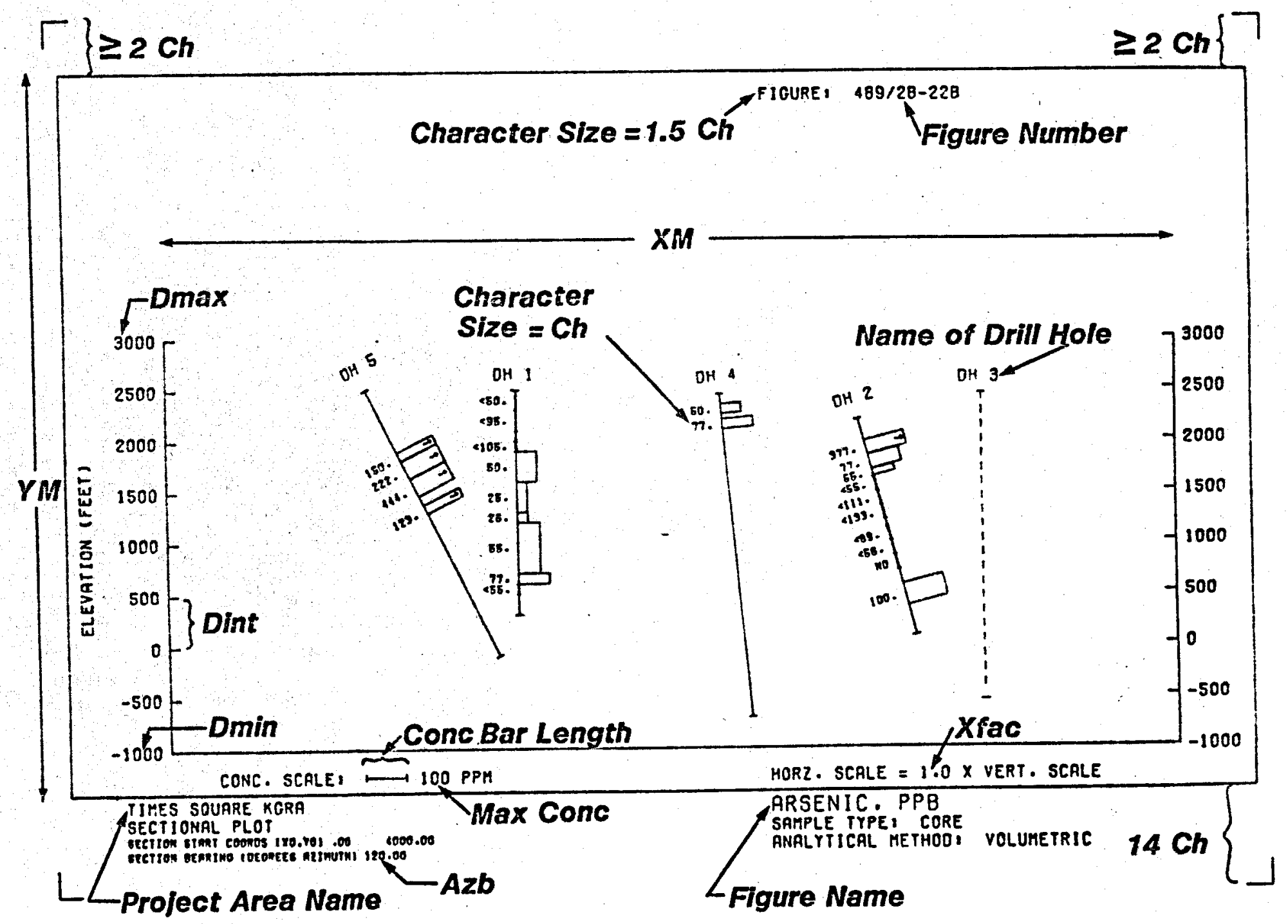


Appendix C

File Structure

$\dot{\theta}$

$\psi$ 


\section{SEC-DATA FILE STRÜCTURE}

RECORD

NUMBER

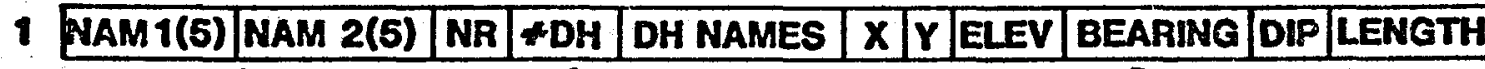
$10 \quad 151506$

Repeat for each DH

2 \begin{tabular}{|l|l|l|l|l|}
\hline UNUSED & FIG NAME & NO.DIGITS & NO. DATA & DRILL HOLE INDICES (ROpOating) \\
\hline
\end{tabular} $\begin{array}{llllll}11 & 6 & 1 & 1 & 1 & 700\end{array}$

\begin{tabular}{|c|}
\hline UNUSED \\
\hline
\end{tabular}

$\begin{array}{llllll}11 & 6 & 1 & 1 & 1 & 700\end{array}$

\begin{tabular}{|l|l|l|l|}
\hline UNUSED & FIG NAME & NO. DATA & FOOTAGE END \\
\hline
\end{tabular}

$\begin{array}{lllllll}11 & 6 & 1 & 1 & 1 & 700\end{array}$

5

\begin{tabular}{|c|c|c|c|}
\hline HEADER & NO. DIG & NO. DATA & PERCENT SILICATE \\
\hline 18 & 1 & 1 & 700
\end{tabular}

6

\begin{tabular}{|c|c|c|c|}
\hline HEADER & NO. DIG & NO. DATA & GEOCHEM VALUES +1 \\
\hline 18 & 1 & 1 & 700
\end{tabular}

\begin{tabular}{|c|c|c|c|}
\hline HEADER & NO. DIG & NO. DATA & GEOCHEM VALUES +2 \\
\hline 18 & 1 & 1 & 700
\end{tabular}

207 \begin{tabular}{c|c|c|}
\hline HEADER & NO. DIG & NO. D \\
\hline 18 & 1
\end{tabular}

18-WORD HEADER (ALPHANUMERIC)

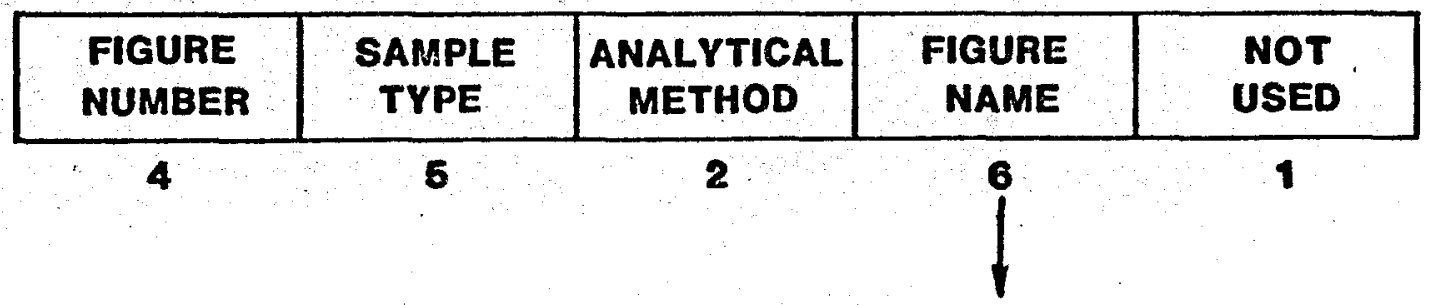

First four Words are fixed data in records $2,3,4$ 


\section{SEC-MERGE FILE STRUCTURE}

\section{WORK RECORD \\ FILE}

NUMBER

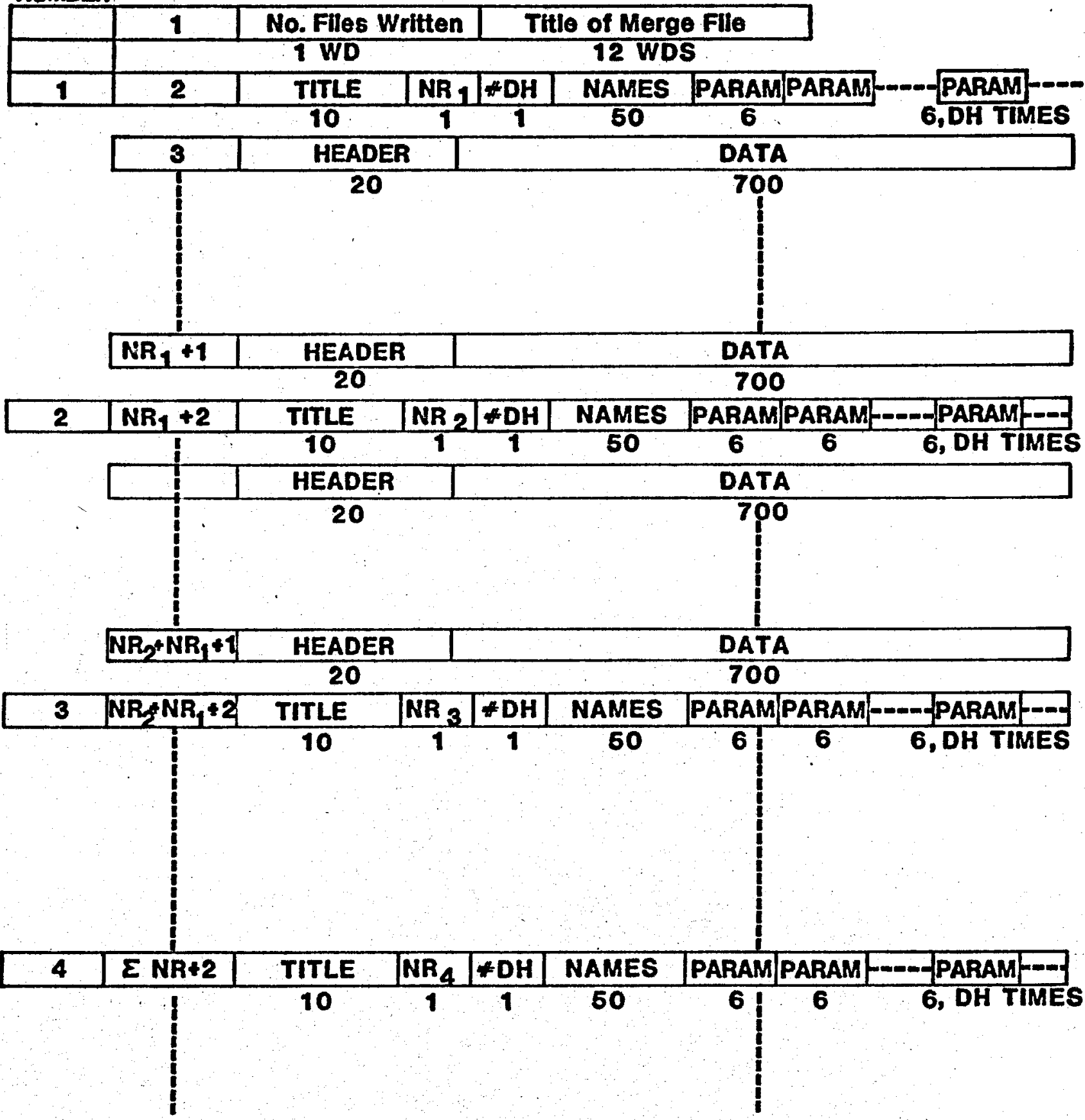


Appendix D

Examples of Terminal Sessions 

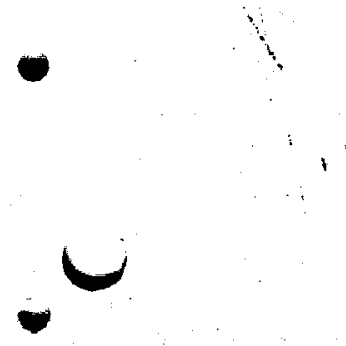

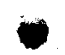

Examples of the Use

of

SEC - IO

D-1 
Input Examples

D-2 
>ARI! SEC-ID. FUH

\begin{tabular}{|c|c|c|}
\hline ENTEP: & $\frac{1}{3}$ & $\begin{array}{l}\text { IHITIAL INFUT } \\
\text { HDIITIDHS } \\
\text { EMIT } \\
\text { LIST } \\
\text { MDVE } \\
\text { AIIIST } \\
\text { TEF!IMATE }\end{array}$ \\
\hline
\end{tabular}

$>1$

ENTER RECDRD NUMEER (I)

$>1$

ENTER PRQJECT AFEA NAME, PT. 1 ( $\$ 9 \% 30$ CHAR)

>RAQSEVELT HQT SPRIHGS KGRA

PRDJECT AFEF NAME, FT. 2 (MIAX 30 CUARS

> EEAVER CDUNTY, UTAH

ENTER NIJHEER OF DOILL HDLES TD IHPUT (I)

$>3$ ENTER MAME DF DFILL HDLE 1 (MAX 6 CHAR)

$>$ UND ENTER $X, Y, E L E Y, B E F R I H E, I I F, L E N G T H$ DF IRILL HQLE 1 (F) $>2500,1300,2500,0,90,2200$

$>$ DOS ENTER NAME DF DRILL HDLE 2 (MAX 6 CHAR)

ENTER $x, Y, E L E Y$, BEARINE, IIP,LENETH DF DPILL HOLE 2 (F)

$>6000,600,2200,45,59,3000$

$>$ TRES

ENTER MFME DF DRILL HDLE 3 (MFX 6 CHAR)

$>8500,2500,2450,0,90,3000$

IIATA STDFEI 


\begin{tabular}{|c|c|c|}
\hline ENTER: & $\begin{array}{l}1 \\
2 \\
4 \\
5 \\
6\end{array}$ & $\begin{array}{l}\text { INIT IAL I } \\
\text { RIIITIOHS } \\
\text { EDIT } \\
\text { LIST } \\
\text { MDVE } \\
\text { AIJUST } \\
\text { TEPMINATE }\end{array}$ \\
\hline
\end{tabular}

$>$
$>9$ ENTER RECDRD NUMEEF (I)

ENTER FIGURE HUMEER (MFX 18 CHAR) フЕDEDT7

ENTER FIGUAE ME!UE (MAX 36 CHAR) $>$ COPPER

ENTER SAMPLE TYPE (MAX 25 CHAR) $>$ WHOLE FOCK

ENTEF ANALYTICAL METHDD (MAX 18 CHAR)

$>$ GRAVIMETRIC $>29,0$ EHTER HIMEER OF IMITIAL IATA VALUES, MDIG (I)

ENTER IIATA (F)

$>46$

$1 ?$

$>562 ?$

37

$>67$

$>78$

$>89$

$4 ?$

57

67

$>-1000000$

77

778

$>55 \quad 9$

$>-2 己$

$>-33$

$>55$

$>66$

107

$11 ?$

127

137

$>-1000000$

10147

$15 ?$

>

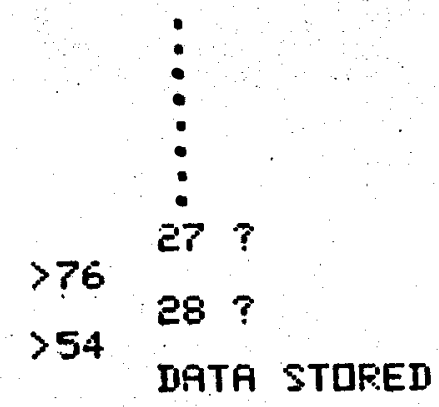

D-4 
Add Examples

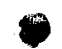

$\bullet$

$\sigma$

$\omega$

D-5 


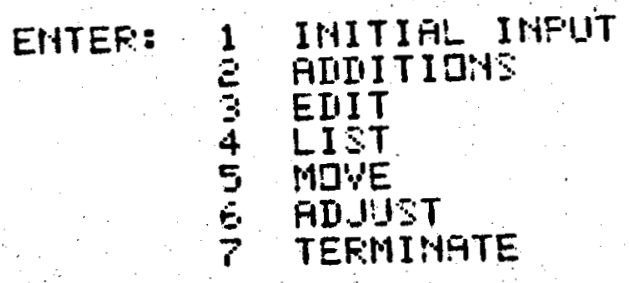

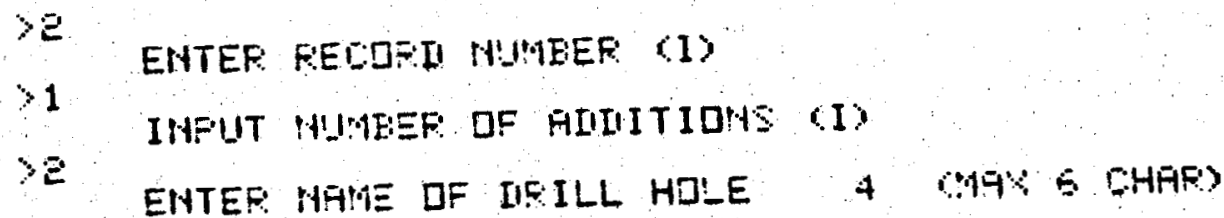

YOUATRE $>4250,300,2450,0,90,3200$ EHTER HUTE OF IFILL HDLE 5 ATS $\triangle$ CHAR)

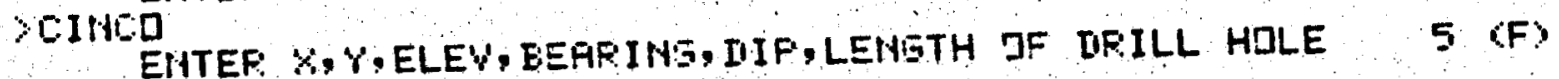
$>800,1700,2500,90,71,3000$ IIHTA STOEEII 

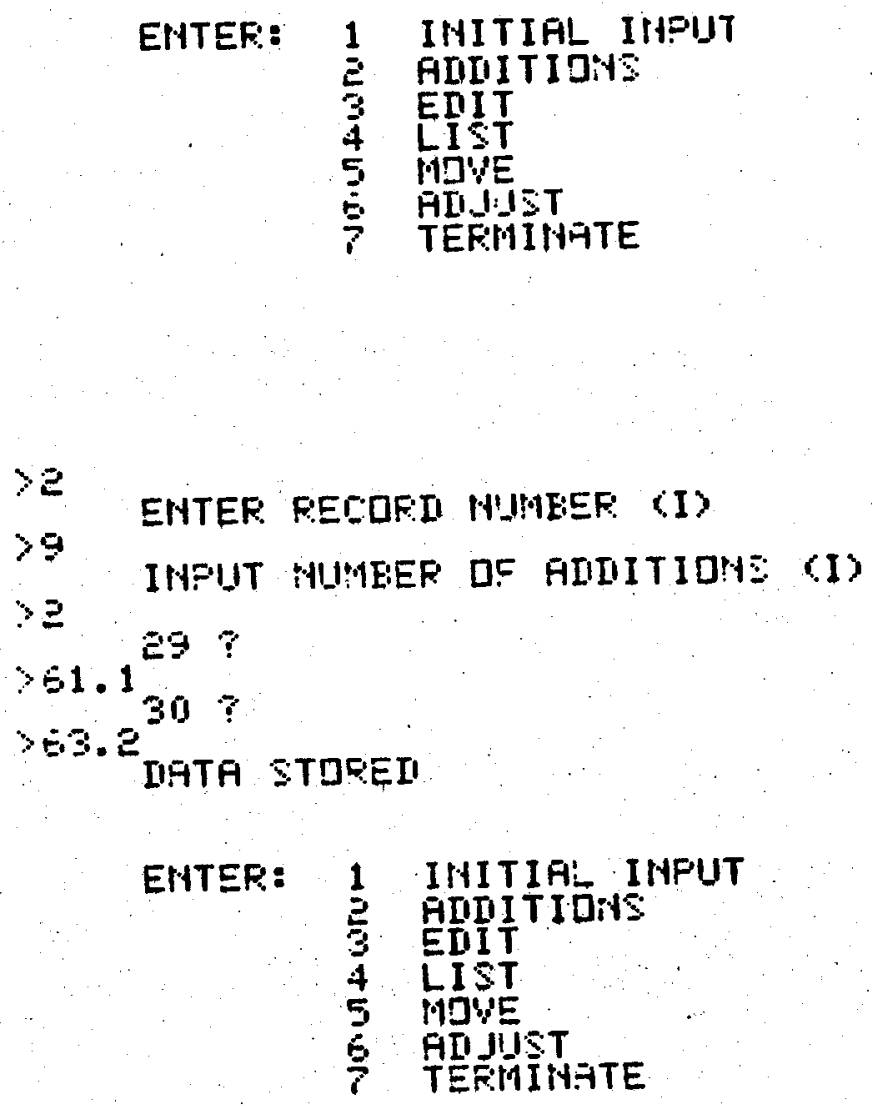
Edit Examples

D-8 


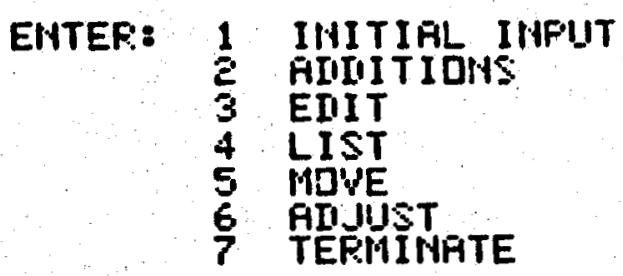

$>3$

$>1$

EHTER RECDFI NUMEER (I)

EHTER: 1 AREA HAHE

2 HD. FECOFIS

3 ND: DF IIFILL HDLES

4 IRILL HDLE THATES

5 IAILL HOLE FAFAMIETERS

6 EHII EIIT REC 1

$>4$

Fe 1

$>\mathrm{TH}-1$

ENTEF: MAME OF IIFILL HDLE 1 (MAX 6 CHAR) $>\mathrm{IH}-\mathrm{Z}$

RCHTE HAME DF IRILL HDLE 2 MAX 6 CHAR)

Fi: 3

$>\mathrm{IH}-3 \mathrm{FC} 4$ $>\mathrm{DH}-4$

EHTER HA:AE DF IPILL HDLE 4 (MAX 6 CHARS

$>$ IH-S ENTEF NAME DF IFILL HDLE 5 MAX 5 CHFF

ENTER: 1 AFEA MAME

E H. FECOFIIS

3 HO. DF IRIILL HOLES

4 IFILL HQLE HATES

5 IFILL HDIE FHEAMETERS

E EHII EIIT PEC 1

$>5$

EHTER: IH IHIEX, COLUMH, VALUE CHANSE - DR $0,0,0(I, I, F)$ >5.2. 1700 EHTER IH IHIEX, COLUMH, VALUE CHAHSE - OR $0,0,0$ (I,I,F)

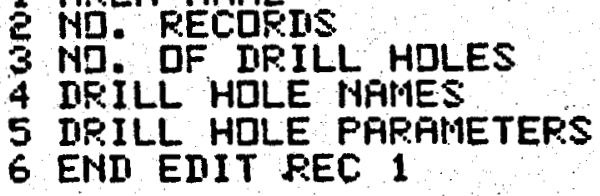

2 ND. RECDRIS

3 HD. DF IRILL HDLES

4 MRILL HOLE MATMES

5 IRILL HQLE PARAMETERS

6 ENI EDIT REC 1

$>6$

IHATH STDFEI 
List Examples 


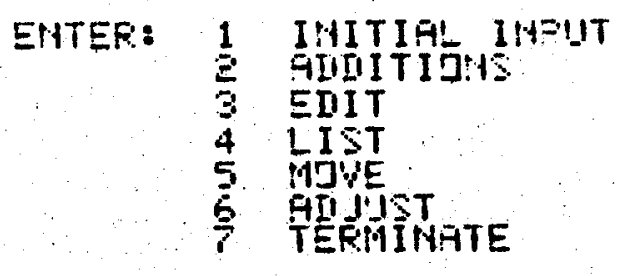

* EHTEP: 1 INIEEX IHTA LIST

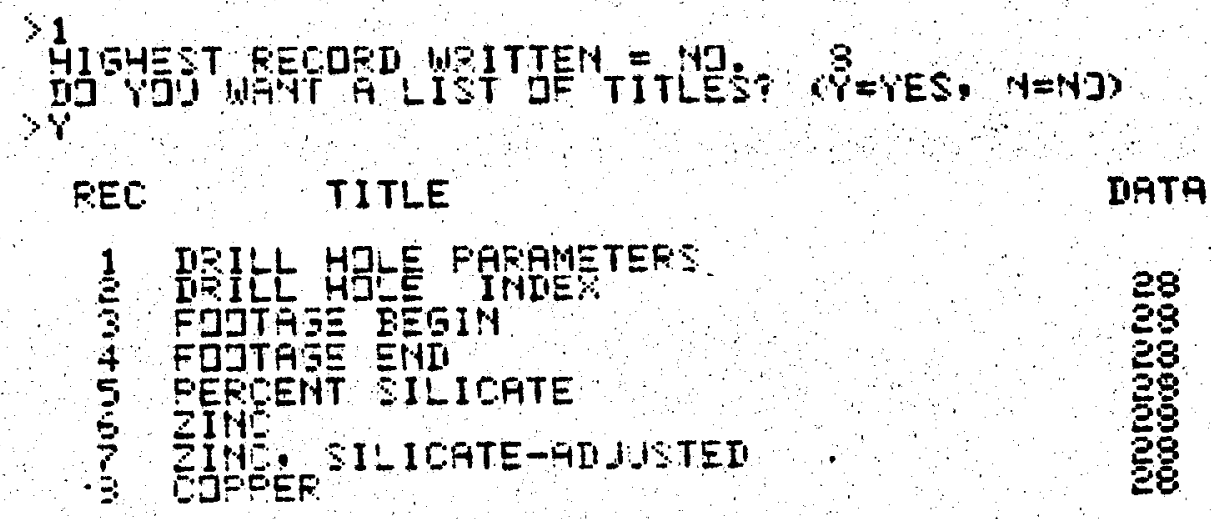




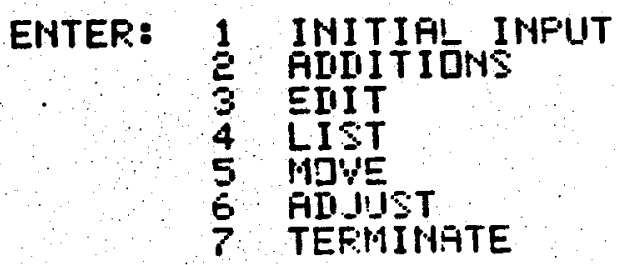

$>4$

ENTEF: 1 IHIEX 2 IATH LIST

$>2$ ENTER MUNEER DF FELEEIIS TU OUTFUT - $\triangle$ MAX

$>1$ ENTER THE 1 FELOFI NUVEEFS TJ DUTFUT

$>1$

AREA HAME: TIMES SOUARE KSEA

HEI SELTIOH ELDT

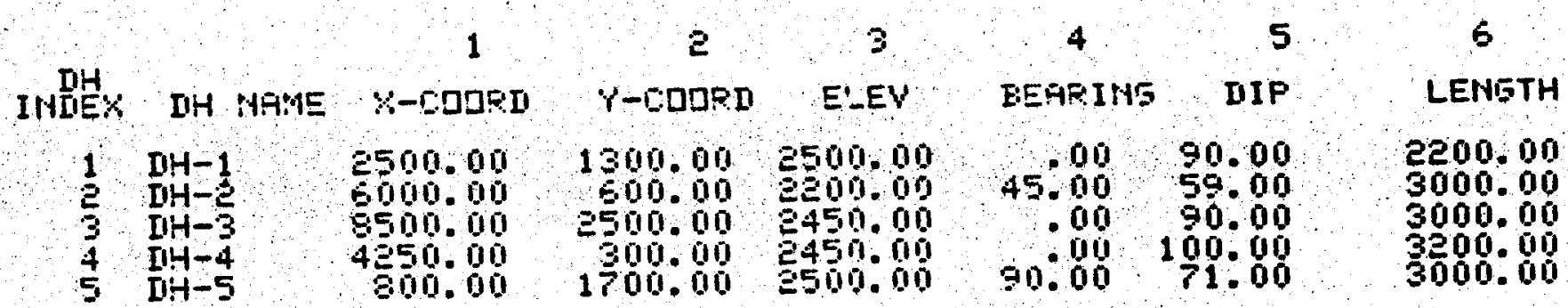

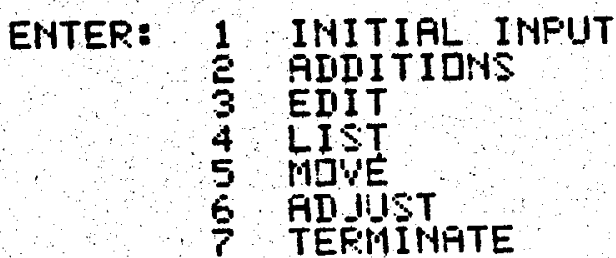


ENTER: 1 IHIIEX

$>e$

ENTER NUMEER DF FECDFUS TD DUTFUT - 6 MFX

$>3$ $>5,6,7$

ENTER THE 3 RECDRI HUMEERS TD DUTPUT

AREA HAME: TIMES SOUARE KGRA

MEW SECTIDH PLDT

CDL 1 IS FERIENT SILICATE

FIGUAEE WO. $=001 / 1 \mathrm{~A}-10 \mathrm{~A}$

SAMFLE TYPE = CORE

FHALYTICAL METHDII= GRAVIMETRIC

MIIAT $=28$

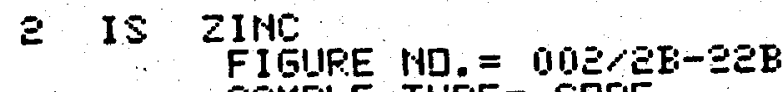

C:LL

SAITFLE TYFE $=$ COF:E

FHHLYTICAL METHDII= ICFD AT ESL

MIIG $=0$

MIAT $=28$

HIIS $=0$

CDL 3 IS ZIHE SILICATE-GIJIITI

MIAT $=28$

SA:ULLE TYFE = COFE

HHALYTICAL METHDII= ICFO AT ESL

NIII $=\quad 0$

123

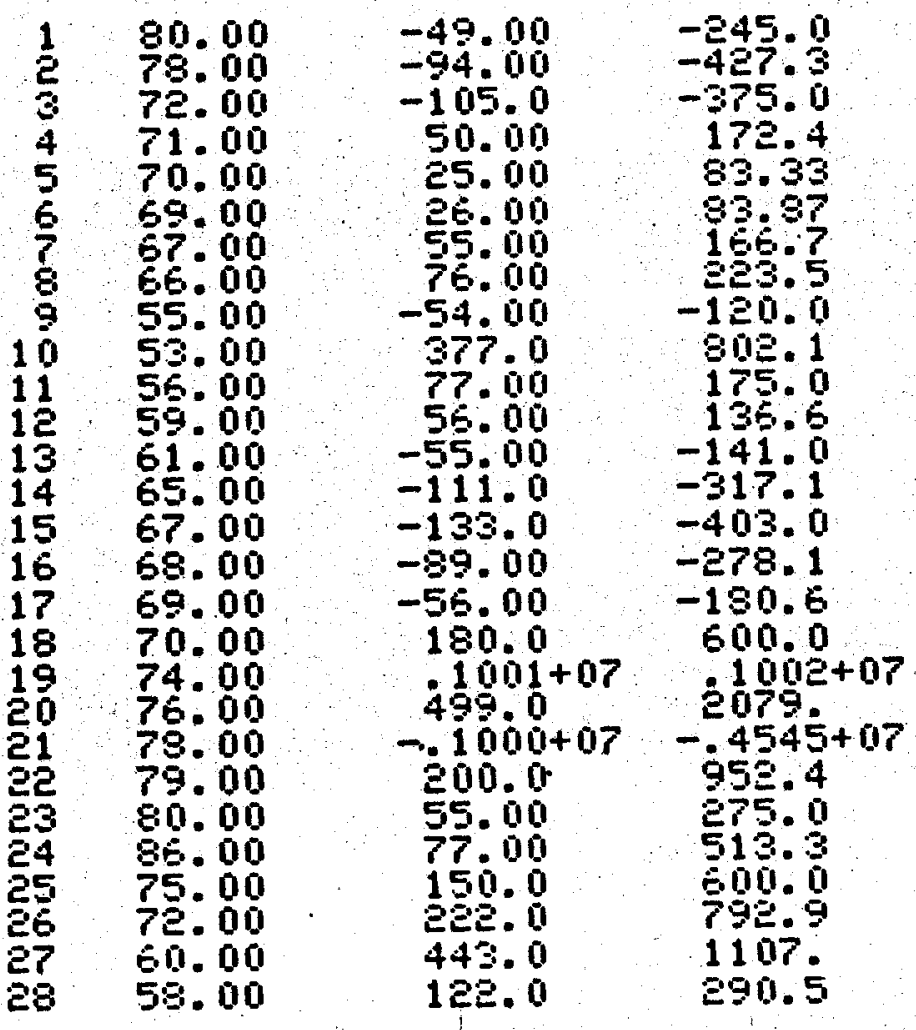


Move Examples

0

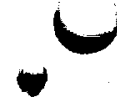

-

$D-16$ 


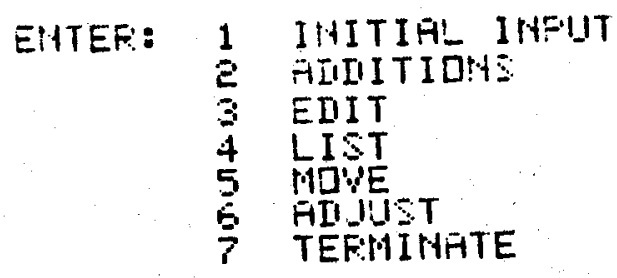

7

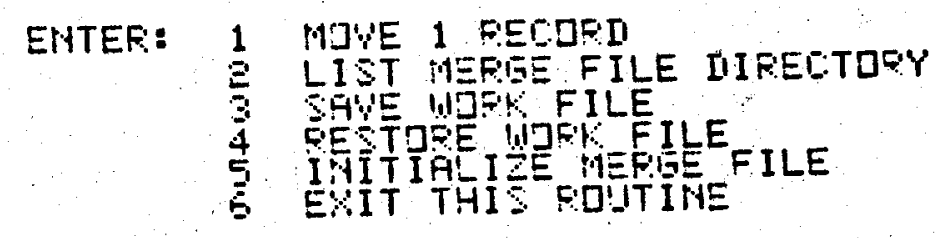

$>1$ ENTER HINEER DF THE FECDFII TD EE MDVED CI $>5$ EHTEF IESTIHATIDH FECORI NUMEE $(1)$

$>9$ RECORI I WRITTEM J:A SECDEII 9 


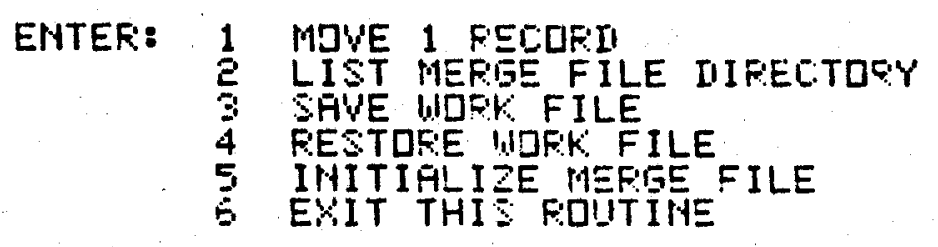

\footnotetext{
$>4$ ENTER FILE NUMEER CID.

- WJKK FILE WILL EE QVEPWRITTEN WITH THIS FILE.

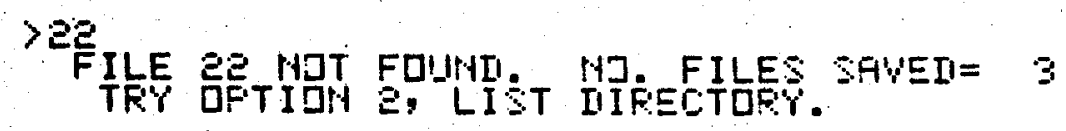

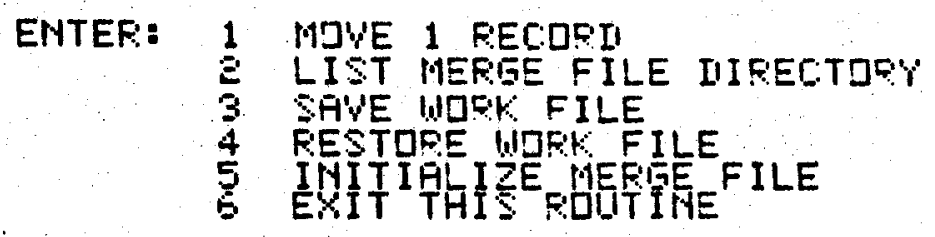

$>E$

$$
\text { IIRECTOFY DF MASTER FILE }
$$

FIRST MERGE FILE FDR EACKUF DF PSFLDT -SEC-IIATA. FILES.

1 TIMES SOUARE KEEA

2 TIMES SOUECRRTERA

3 TIMES GQRECRERS

NEUU SECTIDN PLDT

HEW SECTION PLDT

NEN SECTION FLOT 
ENTER: 1 MDVE 1 FECDFII

2 LIST MERGE FILE DIRECTDPY

3 SRVE WDFK FILE

4 RESTORE WORK FILE

5 IHITIFLIZE MEFGE FILE

6 EXIT THIS ROUTIME

$>3$

FILE ND. 4 HIIIEI TO MEFGE FILE.

EHTER: 1 MUYE 1 RECDRI

S LIST MERGE FILE IIIRECTOPY

4 FESTOSE WOFK FILE

5 INITIALIZE MEFIGE FILE

6 EXIT THIS ROUTIHE

\section{$>4$}

ENTER FILE HUMEEF (I).

WOFK FILE WILL EE JWEFWFITTEN WITH THIS FILE.

$>2$

FILE ? RESTAREI

ENTER:

1 MDVE 1 FEEDFI

3 SIST WEFGE FILE IIFECTDFY

4 FESTDEE UIDFR FILE

$\checkmark$

5 INITIA' I

8

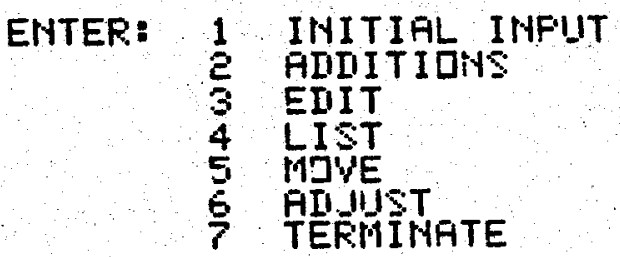

\section{$>7$}

HIRAAL EXIT. 

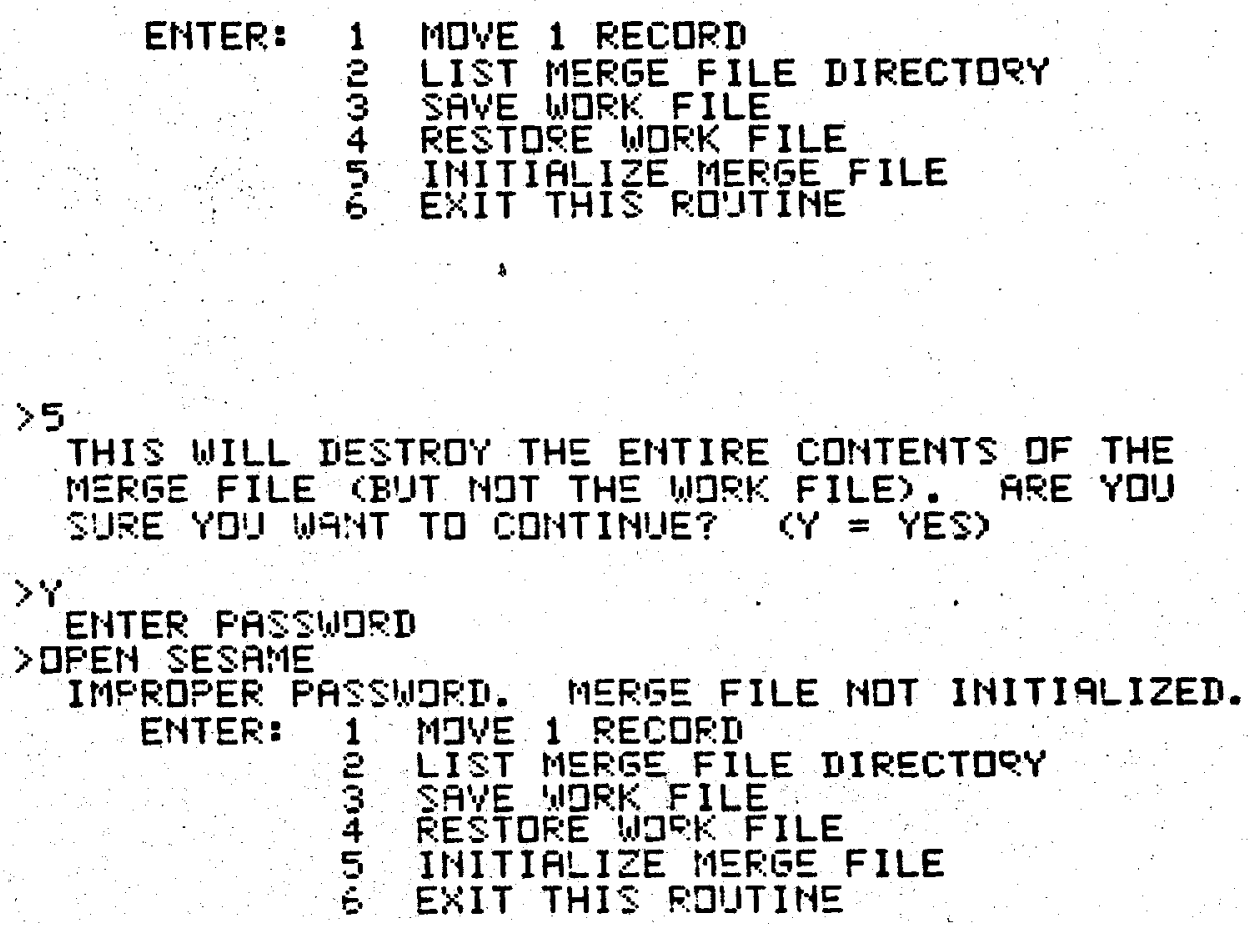
Adjust Example 

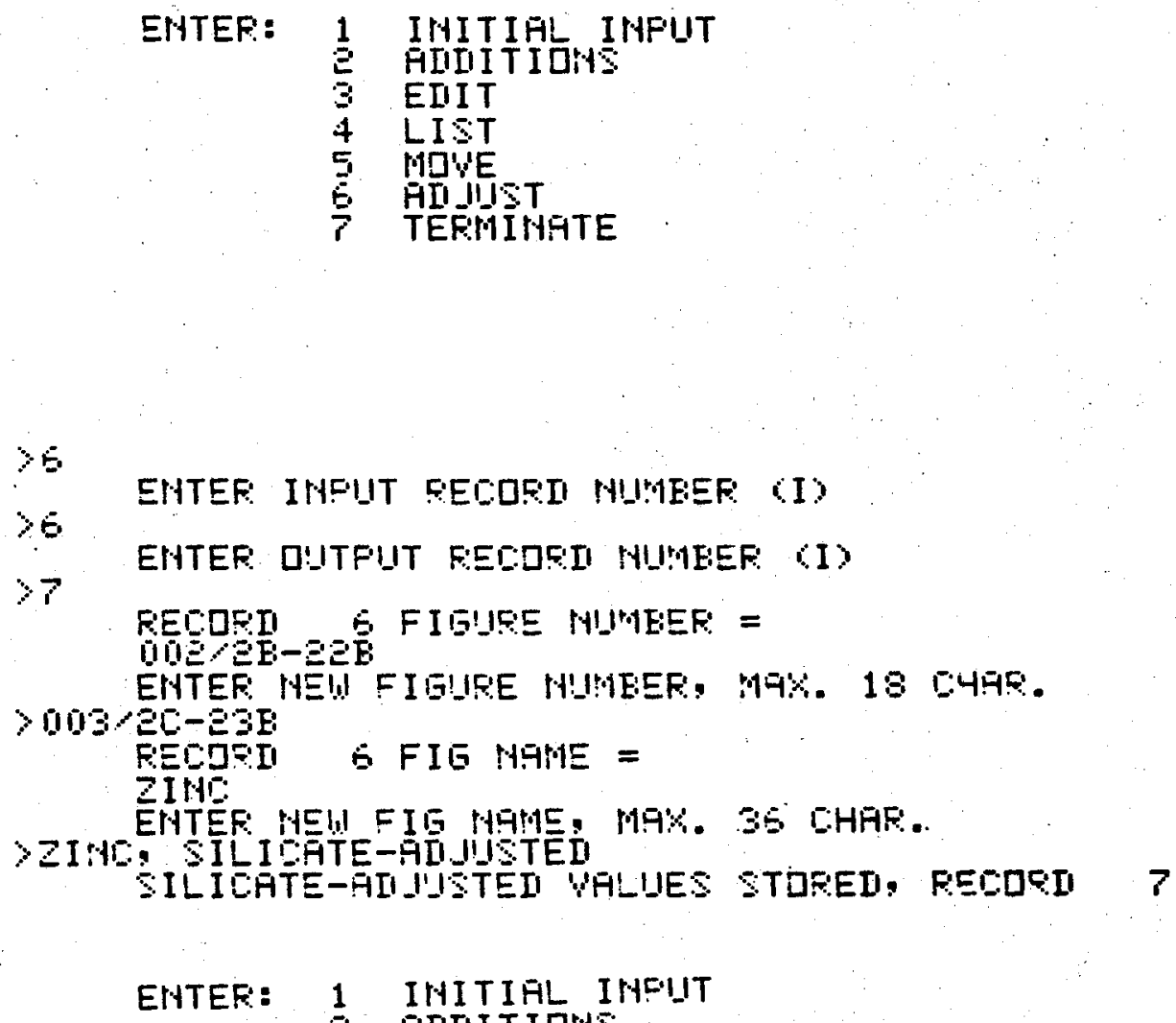

$>7$

MJRMAL EXIT. 


\section{Example of the Use}

of

SEC-PLOT

\section{D-22}


PBAIID SEC-PLUT.RUN

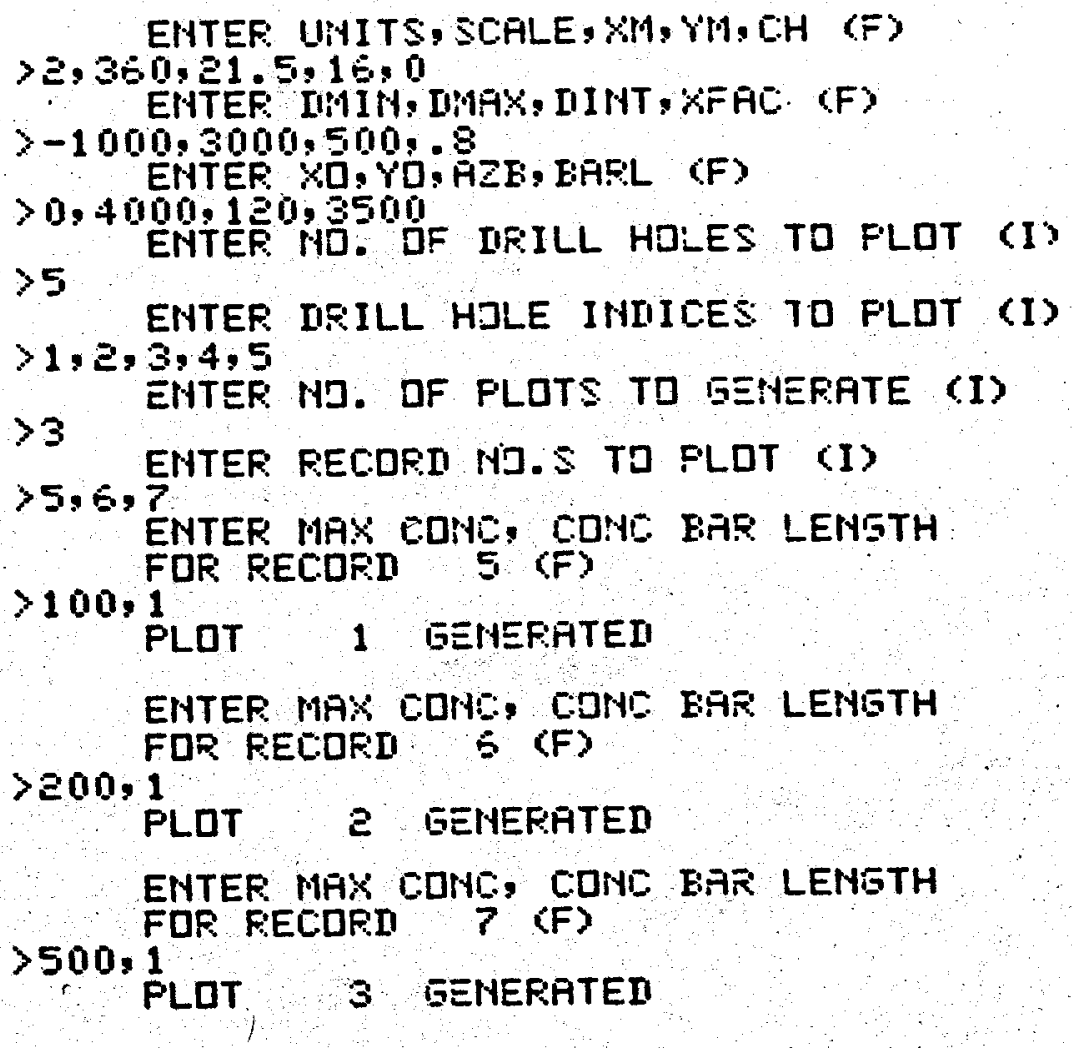

